\title{
Genetic constraints on floral evolution: a review and evaluation of patterns
}

\author{
T-L Ashman and CJ Majetic \\ Department of Biological Sciences, University of Pittsburgh, 4249 Fifth Ave and Ruskin, Pittsburgh, PA 15260, USA
}

\begin{abstract}
The characteristics of flowers influence most aspects of angiosperm reproduction, including the agents of pollination and patterns of mating. Thus, a clear view of the forces that mediate floral phenotypic evolution is central to understanding angiosperm diversity. Here, we inform on the capacity for floral phenotype to respond to selection by reviewing published data on heritabilities and genetic correlations for several classes of floral traits (primary sexual, attraction, mating system) in hermaphroditic plants. We find significant heritability for all floral traits but also variation among them, as well as a tendency for heritability to vary with mating system, but not life history. We additionally test predictions stemming from life history theory (eg, negative covariation between male-female traits and flower
\end{abstract}

size-flower number), and ideas concerning the extent and pattern of genetic integration between flowers and leaves, and between the sexes of dioecious and gynodioecious species. We find mixed evidence for life history tradeoffs. We find strong support for floral integration and its relation with floral morphology (actinomorphy vs zygomorphy) and for a decoupling of floral and vegetative traits, but no evidence that modular integration varies with floral morphology. Lastly, we find mixed evidence for a relationship between the level of sexual dimorphism in attraction traits and the between-sex correlation in gender dimorphic plants.

Heredity (2006) 96, 343-352. doi:10.1038/sj.hdy.6800815; published online 5 April 2006

Keywords: genetic correlation; genetic covariance; flowers; heritability; mating system; sexual dimorphism

\section{Introduction}

In plants, as in any organism, the standing level of genetic variation and covariation is a central determinant of a response to selection, and thus, fundamental to evolution by natural selection (Blows and Hoffmann, 2005). Reviews of empirical work conducted over the last couple of decades have provided a general picture of the strength and shape of selection in the wild (Kingsolver et al, 2001; Geber and Griffen, 2003; Ashman and Morgan, 2004) as well as insight into the levels of genetic variation in functional (Geber and Griffen, 2003), physiological (Arntz and Delph, 2001) and life history characters in wild plants (Mazer and Lebuhn, 1999). But as of yet, we have not developed a general understanding of the pattern of genetic constraint underlying the evolution of floral traits, despite the importance of flowers in plant mating and reproduction, as well as their central role in speciation.

While it is well established that flowers are central targets of selection imposed by pollinators (reviewed in Ashman and Morgan, 2004) and other agents (Strauss, 1997) we still do not have a clear understanding of the degree to which floral phenotypes reflect the action of natural selection relative to underlying genetic or developmental constraints (Conner, 2002). Two outstanding questions in floral biology are: (1) Do floral traits

Correspondence: T-L Ashman, Department of Biological Sciences, University of Pittsburgh, 4249 Fifth Ave and Ruskin, Pittsburgh, PA 15260, USA.E-mail:TIA1@PITT.EDU

Received 20 December 2005; accepted 21 February 2006; published online 5 April 2006 harbor the potential to respond to selection, and if so, which traits or which types of plants have the greatest capacity to respond? and (2) To what degree is floral phenotype constrained by genetic or developmental integration between floral traits, floral and vegetative traits or between sex morphs? Here, we shed light on these general questions by quantitatively assessing published data on heritabilities and genetic correlations for several classes of floral traits. In the next sections, we describe the specific questions we addressed, and the comparisons we performed.

First, we describe the extent and pattern of genetic variation among several categories of floral traits (primary sexual, attraction, and mating system) and among plants with differing mating systems or life histories. An understanding of the variation among traits in their capacity to respond to selection is necessary to make predictions concerning their likely evolutionary trajectory. For instance, whether limited pollination service leads to the evolution of reduced reliance on pollinators (ie, mechanisms of self-pollination) or enhancement of traits that attract pollinators (Ashman and Morgan, 2004), will depend not only on the strength of selection on these traits but also on their ability to respond to selection. Traits may vary in their ability to respond to current selection for a variety of reasons (reviewed in Blows and Hoffmann, 2005). For example, a trait may have low genetic variation relative to other traits because it was subject to strong selection in the past, for example, fitness-related traits such as pollen and ovules (Roff and Mousseau, 1987), or it may have greater sensitivity to environmental variation (plasticity), for example, nectar or female sexual traits (Havens et al, 
1995; Mitchell, 2004). We also sought to determine if genetic variation in floral traits was associated with mating system or life history. Specifically, we determined if genetic variation was lower in self-compatible plants than in self-incompatible ones because the former are on average expected to be more inbred and less genetically variable (Charlesworth and Charlesworth, 1995). We also determined if annuals had lower-genetic variation than perennials because they have shorter generation times (Mazer and Lebuhn, 1999) or their population sizes are more variable and thus, likely to experience bottlenecks (Geber and Griffen, 2003).

Second, we drew on life-history and sex allocation theory, as well as ideas about genetic and developmental integration to guide our exploration of genetic covariation between floral traits, between floral and vegetative traits, and between the sex morphs of gender dimorphic species. Specifically, we explored the level of support for resource allocation tradeoffs that are fundamental assumptions of life history and sex allocation theories. We sought to determine whether male and female traits (Ashman, 2003) or flower size and number (Morgan, 1993; Worley and Barrett, 2000) are negatively genetically correlated. We also determined whether male-female correlations varied with mating system because Mazer and Delesalle (1998) argued that mating system dependent-selection could lead to different patterns of correlation. They proposed that gender in self-compatible autogamous taxa may be under stabilizing selection, leading to positive correlation between male-female traits. In contrast, they argued that in self-incompatible taxa, gender may be under diversifying selection, that is, selection for gender specialists, leading to negative male-female correlations. We then explored the extent of overlap in genetic determination of flower and leaf morphology (eg, Kim et al, 1999), as it informs on whether floral phenotype may also be shaped by selection acting on vegetative traits (or vice versa, eg, Delph et al, 2005). We determined if floral-floral correlations were higher than floral-vegetative correlations because the former are functionally related and may have greater genetic and developmental integration than the latter (Berg, 1960; Conner and Via, 1993; Armbruster et al, 1999; Juenger et al, 2005). We also determined whether this pattern differed between species with actinomorphic and zygomorphic flowers. It has been suggested that plants with zygomorphic flowers receive more specialized pollination and thus may exhibit strong covariation among functionally interacting floral parts but not between floral and vegetative organs (Berg, 1960; Armbruster et al, 1999). In contrast, plants with actinomorphic flowers which receive more generalized pollination may not experience selection for decoupling of floral-vegetative covariation nor strong selection for floral integration, and as a consequence may have lower correlation between floral parts but greater between floral and vegetative ones relative to zygomorphic species (Berg, 1960; Armbruster et al, 1999). Lastly, we explored constraint on the evolution of sexual dimorphism in floral phenotype. Sexual dimorphism can evolve if the genetic correlation between homologous traits expressed in the sex morphs is less than one (Lande, 1980; Ashman, 2003). To test this idea broadly, we determined whether the magnitude of the betweensex correlation could predict the level of sexual dimor- phism in two floral traits (Ashman, 2003) in dioecious and gynodioecious plants. To additionally inform on the capacity for independent evolution, we determined whether male-female correlations are smaller across the sex morphs in dimorphic populations relative to those within hermaphrodites of hermaphroditic populations.

\section{Methods}

\section{Data source}

Our primary data set was compiled from estimates of heritability $\left(h^{2}\right)$ and genetic correlation $\left(r_{\mathrm{g}}\right)$ from 68 studies of hermaphrodite plants published between 1980 and 2005 in American Journal of Botany, Biological Journal of the Linnean Society, Bulletin of the Torrey Botanical Club, Euphytica, Evolution, Evolution and Development, Functional Ecology, Genetics, Heredity, International Journal of Plant Science, Journal of Evolutionary Biology, New Phytologist, Oikos, and The American Naturalist. While there are limitations to the use of these parameters rather than others, for example, genetic (co)variances or coefficients of variation (Houle, 1992), and concerns about bivariate comparisons for assessing constraints (Blows and Hoffmann, 2005) they are the most widely reported parameters and thus offer the greatest potential for comparison at this time. It should be kept in mind, however, that differences in $h^{2}$ could be due to differences in phenotypic variation and/or genetic variation. We considered both broad-and narrow-sense $h^{2}$, since some studies derived estimates based on clones, full-sib or open-pollinated families. The broad-sense $h^{2}$ include nonadditive sources of genetic variation and thus are expected to be larger (Falconer, 1989), but may be appropriate to estimate response to selection for largely inbreeding or vegetatively reproducing plants. We tested for differences between broad- and narrow-sense $h^{2}$ in our data set. For correlations, we pooled all methods of estimation because sample sizes were low. We also compiled a second data set that included seven dimorphic (dioecious or gynodioecious) species. This data set was used to test hypotheses concerning genetic covariation and sexual dimorphism.

\section{Data description}

In our primary data set, we recorded data on three classes of floral traits: (1) primary sexual based on either male or female organs; (2) attraction measured at the flower or inflorescence levels, as well as reward; and (3) mating system. Male primary sexual traits included all aspects of male allocation including pollen production (size and number), and anther (or stamen) size, shape, or number. Female primary sexual traits included aspects of female allocation such as fruit, seed or ovule production (eg, number, mass) and pistil (or style) size, shape, or number. Both male and female traits were measured mostly at the level of individual flowers. Attraction traits at the flower level were confined to those related to corolla, that is, corolla and petal dimensions (eg, length, width, depth, area, and mass), whereas those at the inflorescence level were confined to aspects of flower number, that is, total and daily flower number. Attraction traits pertaining to reward included all aspects of nectar production (ie, rates, volume, concentration, and sugar 
content) and nectary size. Mating system traits included stigma exsertion/position, anther exsertion/position, anther/ovule ratios, stigma-anther distance, proportion male or female flowers, and indices of autonomous autogamy or self-incompatibility. We also recorded data on vegetative traits ( $r_{\mathrm{g}}$ only) for the subset of studies that reported them. These involved measures of leaf and plant dimension (ie, length, width, area, and perimeter; plant height, rosette diameter, and shape), as well as leaf or stem number, and plant dry biomass.

\section{Data analysis}

We included all estimates of $h^{2}$ in the data set even if they were outside theoretical bounds (ie, $0<h^{2}>1$ ). We performed the analyses on these raw values, as well as when extremes were truncated to 0 or 1 and when $h^{2}$ was arcsine transformed. In all cases the results were qualitatively in agreement, so we only present those based on raw data. To meet the assumptions of ANOVA on $r_{\mathrm{g}}$ we identified outliers as greater than $\sim 3 \mathrm{SD}$ from the mean (generally as $-1.25<r_{\mathrm{g}}>1.25$ ) and removed these prior to analyses. Results were qualitatively similar between analyses prior to and following outlier removal, and we present the analyses on the latter. We explored the variation in genetic parameters on two hierarchical levels: (1) an 'All' level which contains estimates for all traits reported for a particular category of interest; and (2) a 'Population' level which contains one randomly chosen $h^{2}$ or $r_{\mathrm{g}}$ per trait category per population. We acknowledge that the 'All' data set is a liberal treatment of the data and that the degrees of freedom for analysis of this data is inflated because all estimates are not independent. However, it does provide our most complete view of genetic parameter variation and we use it to test hypotheses concerning overall trait variation in $h^{2}$ only. The population data set, on the other hand, still suffers from nonindependence, but is more conservative and we use this data set to address the all other hypotheses concerning hermaphrodite species.

We used one-way ANOVA to compare $h^{2}$ across trait types, and two-way ANOVAs to determine if $h^{2}$ or $r_{\mathrm{g}}$ differed among trait and species types (eg, mating system, life history, or floral morphology). If data was lacking (less than five estimates per cell) for a given comparison, we did not perform a statistical analysis.

We assessed the evidence for resource allocation tradeoffs within primary sexual (male, female) or attraction categories (corolla, inflorescence) separately by comparing $r_{\mathrm{g}}$ between traits of the same type (eg, female-female) versus $r_{\mathrm{g}}$ between different types (eg, female-male). As these analyses involved testing nonindependent data for several different hypotheses, we used Bonferroni adjustment of significance values for each analysis.

We determined whether there was a relationship between the level of sexual dimorphism and the betweensex correlation using correlation analysis. We used one value of the between-sex correlation for one attractive trait at each level (flower and inflorescence) per species, when available, and we constructed two different indices of sexual dimorphism: (1) the absolute difference between male (or hermaphrodite) and female trait values relative to their mean value and (2) absolute difference between male (or hermaphrodite) and female trait values relative to the average of the SE (McDaniel, 2005).

\section{Caveats of our analyses}

The results of our analyses must be interpreted with some caution because $h^{2}$ and $r_{\mathrm{g}}$ estimated on multiple traits from the same population of plants are clearly not independent. As a result of this and the fact that many studies do not report the necessary statistics; we did not conduct a formal meta-analysis (Gurevitch and Hedges, 1999). Moreover, there is much debate over whether these genetic parameters can be appropriately subjected to any type of meta-analysis (Markow and Clarke, 1997; Whitlock and Fowler, 1997). As a result of this, some authors have resigned themselves to qualitative comparisons (Kingsolver et al, 2001). However, while our statistical results might need to be viewed with caution, our quantitative approach cannot only inform on the overall patterns but also give us an idea of the magnitude of effects and potential for biologically meaningful differences.

\section{Results}

\section{Description of data set and studies}

The data set contained 604 and 909 estimates of heritability and genetic correlation, respectively, which were derived from 108 populations of 41 species spanning 32 genera and 21 families (Appendix A). Species were primarily self compatible $(71 \%)$, insect-pollinated $(56 \%)$ with zygomorphic flowers $(63 \%)$. Bird- or windpollinated species were rare (two species each). Annuals and perennials were equally represented. Most studies $(66 \%)$ took place under controlled conditions, for example, greenhouses and growth chambers and half of these utilized plant material from full-sib, half-sib, or open-pollinated maternal families. Only 10 studies of nine species (from seven genera and six families) reported vegetative-floral trait correlations for 15 populations. Data on dimorphic species came from seven studies of seven species (Appendix A).

\section{Pattern of $h^{2}$ : distribution across traits}

For all classes of floral traits, $h^{2}$ (Figure 1) was normally distributed with a grand mean of 0.39 , which was significantly different from $0(P<0.001)$. Mean $h^{2}$ was highest for corolla, male and mating system traits, lowest for reward and female traits and intermediate for flower number (Figure 1). There were significant $(P<0.0001)$ differences in $h^{2}$ among traits in the 'All' data set even after Bonferroni adjustment, but not the 'Population' data set, although the patterns were the same. While broad sense $h^{2}$ were slightly larger, they did not differ from narrow sense $h^{2}(P>0.10)$ and thus all were pooled for the majority of subsequent analyses.

\section{Pattern of $h^{2}$ : mating system}

Sufficient data were available only to compare selfcompatible and self-incompatible species with respect to narrow-sense $h^{2}$ for male, female and corolla traits. Across all three traits, self-compatible species had lower $h^{2}$ than self-incompatible species $(P<0.04$; Figure 2; Table 1). However, this did not retain significance after Bonferroni correction. 
Pattern of $h^{2}$ : life history

Differences in $h^{2}$ between annuals and perennials were always slight and nonsignificant (annuals vs perennial pooled across all traits: $0.40 \pm 0.026$ vs $0.40 \pm 0.025$; Table 1).

Pattern of $r_{\mathrm{g}}$ : evidence for tradeoffs?

Across traits, we detected a general pattern of significant positive covariation (all $r_{\mathrm{g}}>0$; significant after Bonferroni correction; Figure 3; Table 1), with one exception. For primary sexual traits there were no significant differences among $r_{g}$, and thus no evidence for a tradeoff between male and female traits within flowers (Figure 3 top; all $P>0.1$ ). In contrast, there were differences in correlation for attraction traits that remained significant

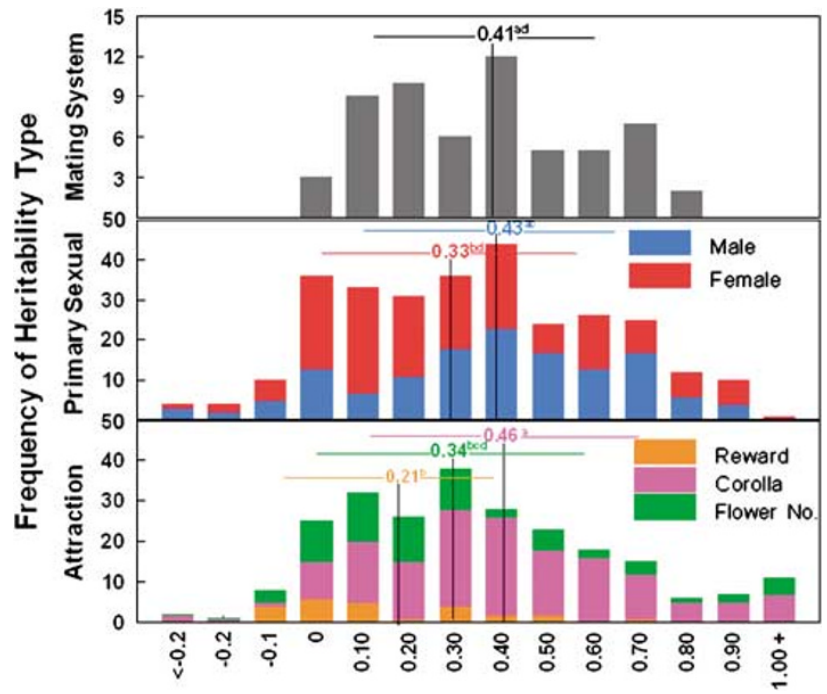

Figure 1 Frequency histograms of $h^{2}$ for floral traits by category, that is, mating system (top), primary sexual traits (middle), and attraction (bottom). Mean and SE for each trait type is denoted by a vertical and horizontal bar, respectively. Means that do not share letters are significantly different from each other as determined by a Tukey's test. after Bonferroni correction (Figure 3 bottom; $P<0.0002$ ). Correlations between corolla size traits or between inflorescence traits were high and positive $(P<0.001)$ whereas $r_{\mathrm{g}}$ across corolla and inflorescence traits was not significantly different from $0(P>0.30)$. In fact, when only narrow-sense correlations are considered, the average $r_{\mathrm{g}}$ across corolla and inflorescence traits is negative $(-0.03 \pm 0.077)$, suggesting that the difference in correlation is due to an underlying tradeoff.

We also tested whether male-female $r_{\mathrm{g}}$ was lower in self-compatible species than self-incompatible ones, but found no significant difference (SC: $0.47 \pm 0.016$ vs SI: $0.38 \pm 0.109 ; N=10 ; P>0.50)$.

\section{Pattern of $r_{\mathrm{g}}$ : floral versus vegetative}

We compared correlations between floral traits (sexual and attraction traits only) to those between floral and vegetative traits and found the average level of $r_{\mathrm{g}}$ between floral traits $(0.32 \pm 0.028)$ was significantly $(P<0.008)$ higher than that between floral and vegetative traits $(0.15 \pm 0.067)$. In fact, the correlation between floral and vegetative traits was not significantly different from 0 after Bonferroni correction (Table 1).

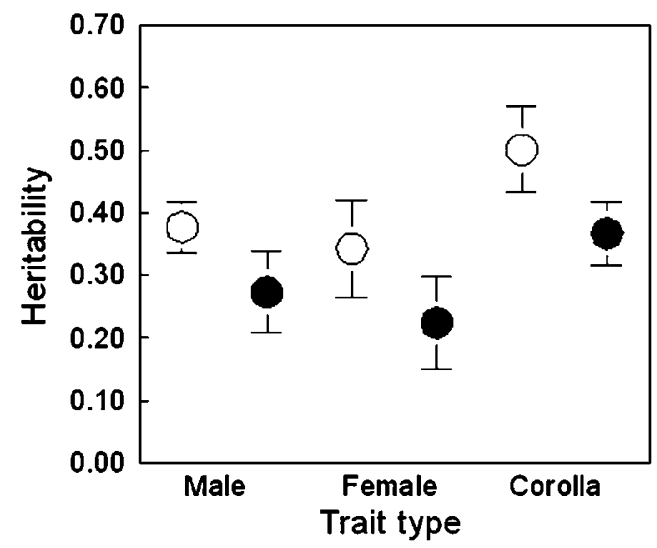

Figure 2 Mean $h^{2}( \pm \mathrm{SE})$ for male, female and corolla traits for selfincompatible (empty symbols) and self-compatible (filled symbols) plants. Sample sizes are 21-7.

Table 1 Summary of predictions and supporting evidence

\begin{tabular}{|c|c|c|}
\hline & Prediction & Significant supporting evidence? \\
\hline \multicolumn{3}{|c|}{ Hermaphrodite } \\
\hline \multirow[t]{3}{*}{$h^{2}$} & Trait variation & $Y_{e s}^{* a}$ \\
\hline & Self-compatible $<$ self-incompatible & Yes \\
\hline & Annual $<$ Perennial & No \\
\hline \multirow[t]{5}{*}{$r_{\mathrm{g}}$} & Male-female tradeoffs & No \\
\hline & Flower size and number tradeoffs & Yes* \\
\hline & Floral-floral > floral-vegetative & Yes* \\
\hline & Floral-floral: actinomorphic $<$ zygomorphic & Yes* \\
\hline & Floral-vegetative: actinomorphic > zygomorphic & No \\
\hline \multicolumn{3}{|c|}{ Dimorphic } \\
\hline \multirow[t]{2}{*}{$r_{\mathrm{g}}$} & Male-female tradeoff: dimorphic $>$ hermaphrodite & No \\
\hline & Sexual dimorphism inversely proportional to the between-sex correlation & No \\
\hline
\end{tabular}

aSignificant only in the 'All' data set although pattern the same in the 'Population' data set.

A 'Yes' in the supporting evidence column denotes significant pattern. An asterisk denotes results that remained significant after Bonferroni correction. 


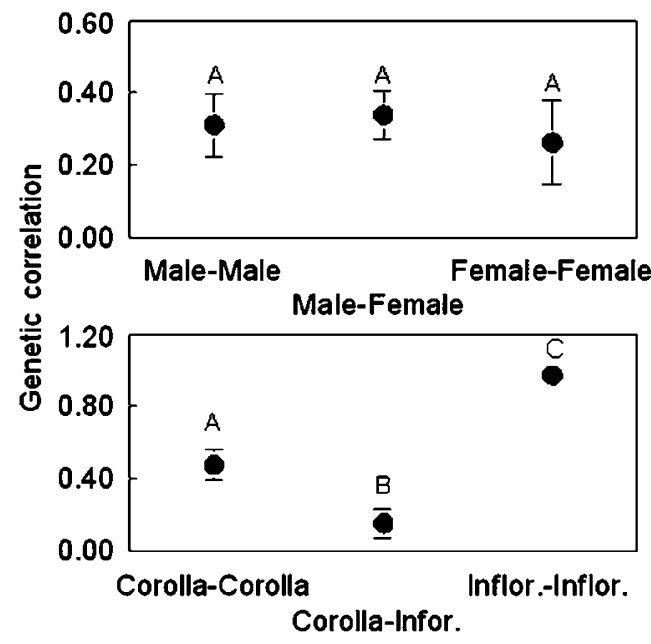

Figure 3 Mean $r_{g}( \pm \mathrm{SE})$ for primary sexual traits (top) and attraction traits (bottom). Primary sexual traits included traits associated with male and female investment. Attraction traits include those measured at the level of flowers (eg corolla size) or whole inflorescences (eg, flower number). Sample sizes are 53-36 for sexual, 21-5 for attraction, respectively. Within a data set, means not sharing letters are significantly different as determined by a Tukey's test.

\section{Pattern of $r_{\mathrm{g}}$ : floral morphology}

The average level of $r_{\mathrm{g}}$ between floral traits was significantly greater in zygomorphic flowers than actinomorphic flowers, even after Bonferroni adjustment $(0.51 \pm 0.054$ vs $0.23 \pm 0.030 ; P<0.0001$; Table 1$)$. The strength of the difference between floral-floral and vegetative-floral correlations did not differ between flower types (trait by morphology interaction: $P>0.15$ ), indicating that plants with different floral morphologies do not differ in the level of floral-vegetative integration.

\section{Pattern of $r_{\mathrm{g}}$ : gender dimorphism}

Male-female correlations across sex morphs in gender dimorphic species were smaller than those within hermaphrodites of hermaphroditic species $(0.14 \pm 0.265$ vs $0.34 \pm 0.067)$ but these differences were based on too small a sample size for gender dimorphics $(N=3)$ to warrant a statistical test. Although a clear pattern of higher sexual dimorphism for traits with low betweensex correlation exists for two species (gynodioecious Fragaria virginiana and dioecious Silene latifolia), this pattern did not exist in gynodioecious Lobelia siphilitica, nor across all species combined, regardless of the index of dimorphism used $(r=0.09,0.07$; both $P>0.5$; Figure 4).

\section{Discussion}

Patterns of $h^{2}$ for floral traits

Overall patterns: The mean estimates of $h^{2}$ reviewed here suggest significant genetic variation exists in floral traits and is on par with average heritabilities found in other reviews, for example, 0.43 for physiology, 0.23 for vegetative morphology (Geber and Griffen, 2003). These data also suggest that selection on floral traits may not

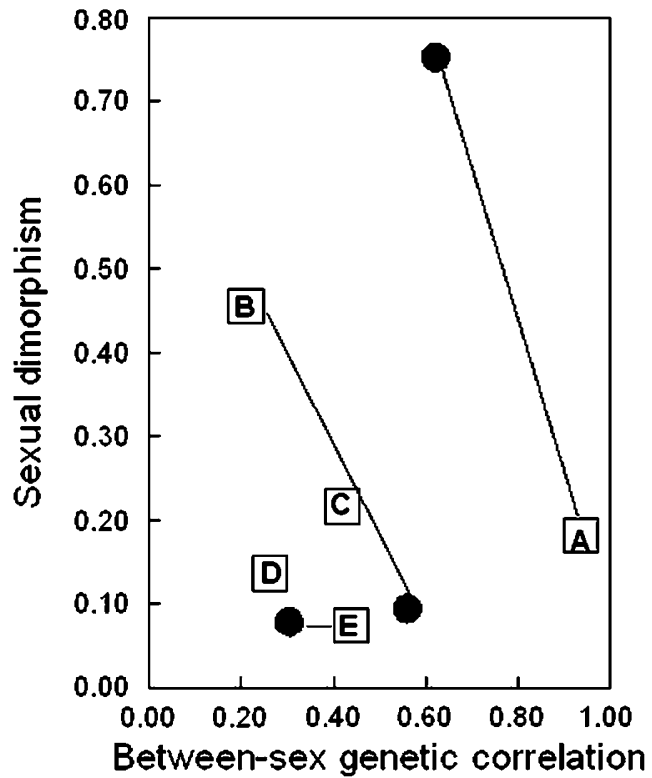

Figure 4 The relationship between the between-sex genetic correlation and the level of sexual dimorphism (absolute difference between the means of the sexes relative to their average standard error) for two attraction traits (corolla size - squares, flower number - circles). Lines connect traits measured in the same species. A - Fragaria virginiana, B - Silene latifolia, C - Phacelia lanceolata, D - Ecbalium elatrium, E - Lobelia siphilitica)

often be limited by lack of genetic variation. However, because most of the studies reviewed were conducted under controlled conditions and thus, may over estimate $h^{2}$ under natural conditions (Conner et al, 2003), this conclusion should be viewed with some caution. If one can generalize across species, then these data also suggest that plants harbor an equivalent capacity to respond to selection on corolla or mating system traits. On the other hand, selection response may be expected to be slower with respect to reward and female traits (Figure 1). These patterns are more in line with the idea that high environmental variability, rather than strong past selection, may be the cause of variation in $h^{2}$. Similar conclusions were drawn in a review of plant functional traits (Geber and Griffen, 2003). The only way to truly understand the genesis of these patterns, however, is for more studies to report variance components as well as $h^{2}$. For instance, if both the additive genetic and environmental components of variance are reported then their relative contributions to $h^{2}$ for different traits can be assessed.

Variation associated with mating system and life history: Even though self-compatible species may have mixed mating systems rather than entirely selfing ones (Goodwillie et al, 2005), we found evidence for lower $h^{2}$ in self-compatible species compared to self-incompatible ones, although this did not retain statistical significance after correction for multiple tests. Nevertheless, it is suggestive of lower standing levels of genetic variance in more inbred species (Figure 2). This result is in accord with published patterns of lower $h^{2}$ for flowering date (Mazer and Lebuhn, 1999), and plant functional traits (Geber and Griffen, 2003) in self-compatible relative to incompatible species, and a reduction in the genetic 
coefficient of variation for a variety of plant traits with increasing selfing rate (Charlesworth and Charlesworth, 1995). Together these studies begin to lend support to the idea that mating system affects the standing level of genetic variation, and thus the potential for evolutionary response. Future work, however, should endeavor to correlate realized selfing rate with genetic variation of a given trait.

In contrast, we found no evidence for differences in $h^{2}$ with life history, a result that is also in accord with the findings of Geber and Griffen (2003) for functional traits, but not with Mazer and Lebuhn (1999), who found lower $h^{2}$ in annuals than perennials for a wide variety of life history traits. Taken together these findings suggest that differences in $h^{2}$ between annuals and perennials depends heavily on how tightly the traits are tied to life history. The lack of difference for floral and functional traits may be due to other features that affect overall variation, such as seed banks buffering against loss of genetic variation in annuals (Nunney, 2002), or the fact that most perennials studied are relatively short-lived and herbaceous, and thus subject to similar fluctuations in population size as annuals. More studies of longerlived, woody species would be needed to assess this latter hypothesis.

\section{Patterns of genetic covariation}

Patterns predicted from life-history and sex allocation theory: Our results suggest two general patterns with respect to tradeoffs: (1) that $r_{\mathrm{g}}$ between male and female traits is often positive in hermaphrodite species; (2) that tradeoffs may be more likely across modules rather than within modules.

First, we found positive male-female $r_{\mathrm{g}}$ across hermaphrodite species (Figure 3). Positive correlation may reflect greater genetic variation in resource acquisition than in allocation (Van Noordwijk and de Jong, 1986), or it could have a selective basis. Mazer and Delesalle (1998) have argued that pollen-ovule $r_{\mathrm{g}}$ may be under stabilizing selection in autogamously selfing species whereas in outcrossing species it may be under diversifying selection. Although not statistically significant, our data on the variation in male-female $r_{\mathrm{g}}$ with mating system is consistent with this argument, as is the data reviewed by Ashman (2003). We will need comparative studies that combine estimates of male-female $r_{\mathrm{g}}$ with estimates of selection on sex allocation or selfing rate to fully test these ideas.

In contrast to the pervasive positive correlation within modules for attraction there was no significant correlation between modules. Specifically, although corolla traits were significantly positively correlated, corolla and inflorescence traits were not (or were negatively) correlated. This may indicate a high level of genetic and developmental integration within flowers (Juenger et al, 2005), negative pleiotropy across flowering modules, for example, size and number (Caruso, 2004), or both. Artificial selection experiments (Conner, 2002) or QTL mapping studies (Juenger et al, 2005) would be powerful ways to address these hypotheses. For instance, if artificial selection can not break up correlations (Worley and Barrett, 2000) or QTL colocalize (Juenger et al, 2005) then pleiotropy, or very tight linkage, is likely.
Patterns predicted from developmental integration within flowers vs between flowers and vegetative organs: We found support for developmental integration on two fronts: (1) we found stronger integration of traits within flowers and that this was greater in plants with zygomorphic flowers compared to those with actinomorphic flowers; (2) we found stronger correlation among floral traits than between floral and vegetative traits. However, we did not find support for the prediction that floral-vegetative integration should vary with flower morphology. These results suggest that flowers and leaves, despite having some level of overlap in gene expression (eg, Kim et al, 1999) also maintain distinct levels of developmental integration, or restricted sets of pleiotropic loci. Additionally, while the level of integration is increased in zygomorphic flowers, the across-module variation does not differ from that of plants with actinomorphic flowers. While a potentially interesting conclusion, one must note that the floralvegetative comparisons are based on relatively few plant species, and thus more data must be collected before a final conclusion is drawn. A critical next step in addressing this hypothesis will be to compare the floralvegetative G-matrices for pairs of related species that differ primarily in floral morphological type. In addition, taxa for which changes in flower shape have been tied to the function of one or a few genes can be used to evaluate the effects of these genes on vegetative traits (eg, Costa et al, 2005).

\section{Patterns of $r_{\mathrm{g}}$ and sexual dimorphism}

Across species we did not find support for the predicted inverse relationship between sexual dimorphism and between-sex genetic correlation. This pattern was, however, apparent in two of the three species for which both attractive traits had been measured. It is interesting to note that these two species are dioecious (Silene latifolia) or gynodioecious with high female frequencies (Fragaria virginiana) relative to the third species (Lobelia siphilitica), which is gynodioecious, but with a very low frequency of females. This may suggest that genetic architecture changes as gender dimorphism evolves. Only when more data on additional species is collected will we be able to confirm this. In addition, studies within species that artificially select for increased or decreased sexual dimorphism will also be useful in assessing the liability of the between-sex correlation. It is also important to note that the between-sex correlation is not the only genetic correlation that influences the response to selection in gender dimorphic species, and correlations within the sex morphs could be responsible for the lack of pattern across species (Ashman, 2005).

\section{Conclusions}

Our review and analysis of genetic (co)variation in primarily hermaphroditic flowering plants has pinpointed several areas where the response to selection on floral phenotype is likely to be constrained by genetic architecture. First, hermaphroditic flowering plants retain a significant capacity to respond to selection on floral phenotype, but this varies with mating system such that self-compatible species may be less able to respond to similar selection than self-incompatible ones. 
Second, while pervasive positive genetic correlations between male-female traits may constrain the evolution of gender specialists in outcrossing species, such correlations could facilitate the response to stabilizing selection in autonomously selfing species. Third, strong levels of genetic integration within flowers of zygomorphic plants but not actinomorphic ones might indicate that evolving zygomorphy limits a species' evolutionary options, at least with respect to floral phenotype. Fourth, evidence that floral and vegetative traits are decoupled in both types of plants suggests that vegetative and floral modules may be relatively free to evolve to separate optima.

\section{Acknowledgements}

This work was supported by NSF grants (DEB 0108099, 0449488) to T-LA and a NSF graduate fellowship to CJM. The authors thank J Steets and two anonymous reviewers for insightful comments on an earlier draft.

\section{References}

Armbruster WS, Di Stillo VS, Tuxill JD, Flores TC, Velasquez Runk JL (1999). Covariance and decoupling of floral and vegetative traits in nine neotropical plants: a reevaluation of Berg's correlation-pleiades concept. Am J Bot 86: 39-55.

Arntz AM, Delph LF (2001). Pattern and process: evidence for the evolution of photosynthetic traits in natural populations. Oecologia 127: 455-457.

Ashman T-L (2003). Constraints on the evolution of dioecy and sexual dimorphism: field estimates of quantitative genetic parameters for reproductive traits in three populations of gynodioecious Fragaria virginiana. Evolution 57: 2012-2025.

Ashman T-L (2005). The limits on sexual dimorphism in vegetative traits in a gynodioecious plant. Am Nat 166: S5-S16.

Ashman T-L, Morgan MT (2004). Explaining phenotypic selection on plant attractive characters: male function, gender balance or ecological context? Proc Royal Soc London: B 271: 553-559.

Berg RL (1960). The ecological significance of correlation pleiades. Evolution 14: 171-180.

Blows MW, Hoffmann AA (2005). A reassessment of genetic limits to evolutionary change. Ecology 86: 1371-1384.

Caruso CM (2004). The quantitative genetics of floral trait variation in Lobelia: potential constraints on adaptive evolution. Evolution 58: 732-740.

Charlesworth D, Charlesworth B (1995). Quantitative genetics in plants: effect of the breeding system on genetic variability. Evolution 49: 911-920.

Conner J, Franks R, Stewart C (2003). Expression of additive genetic variances and covariances for wild radish floral traits: comparison between field and greenhouse environments. Evolution 57: 487-495.

Conner J, Via S (1993). Patterns of phenotypic and genetic correlations among morphological and life history traits in wild radish. Evolution 47: 704-711.

Conner JK (2002). Genetic mechanisms of floral trait correlations in a natural population. Nature 420: 407-410.

Costa MMR, Fox S, Hanna AI, Baxter C, Coen E (2005). Evolution of regulatory interactions controlling floral asymmetry. Development 132: 5093-5101.

Delph LF, Gehring JL, Arntz AM, Levri M, Frey FM (2005). Genetic correlations with floral display lead to sexual dimorphism in the cost of reproduction. Am Nat 166: 31-41.
Falconer DS (1989). Introduction to Quantitative Genetics, 3rd edn. Wiley and Sons: New York, NY.

Geber MA, Griffen LR (2003). Inheritance and natural selection on functional traits. Int I Plant Sci 164: S21-S42.

Goodwillie C, Kalisz S, Eckert CG (2005). The evolutionary enigma of mixed mating systems in plants: occurrence, theoretical explanations, and empirical evidence. Ann Rev Ecol, Evol Syst 36: 47-79.

Gurevitch J, Hedges LV (1999). Statistical issues in ecological meta-analysis. Ecology 80: 1142-1149.

Havens K, Preston KA, Richardson C, Delph LF (1995). Nutrients affect allocation to male and female function in Abutilon theophrasti (Malvaceae). Am J Bot 82: 726-733.

Houle D (1992). Comparing evolvability and variability of quantitative traits. Genetics 130: 195-204.

Juenger T, Perez-Perez JM, Bernal A, Micol JL (2005). Quantitative trait loci mapping of floral and leaf morphology traits in Arabidopsis thaliana: evidence for modular genetic architecture. Evol Dev 7: 259-271.

Kim GT, Tsukaya H, Saito Y, Uchimiya H (1999). Changes in the shapes of leaves and flowers upon overexpression of cytochrome P450 in Arabidopsis. Proc Nat Acad Sci USA 96: 9433-9437.

Kingsolver JG, Hoekstra HE, Hoekstra JM, Berrigan D, Vignieri SN, Hill CE et al (2001). The strength of phenotypic selection in natural populations. Am Nat 157: 245-261.

Lande R (1980). Sexual dimorphism, sexual selection and adaptation in polygenic characters. Evolution 34: 292-305.

Markow TA, Clarke GM (1997). Meta-analysis of heritability of developmental stability: a giant step backward. J Evol Biol 10: 31-37.

Mazer SJ, Delesalle VA (1998). Contrasting variation within and covariation between gender-related traits in autogamous versus outcrossing species: alternative evolutionary predictions. Evo Ecol 12: 403-425.

Mazer SJ, Lebuhn GL (1999). Genetic variation in life history traits: heritability estimates within and genetic differentiation among populations. In: Vuorisalo TO, Mutikainen PK (eds) Life History Evolution in Plants. Kluwer Academic Publishers: Dordrecht, The Netherlands. pp 85-171.

McDaniel SF (2005). Genetic correlations do not constrain the evolution of sexual dimorphism in the moss Ceratodon purpureus. Evolution 59: 2353-2361.

Mitchell RJ (2004). Heritability of nectar traits: why do we know so little? Ecology 85: 1527-1533.

Morgan M (1993). Fruit to flower ratios and trade-offs in size and number. Evol Ecol 7: 219-232.

Nunney L (2002). The effective size of annual plant populations: the interaction of a seed bank with fluctuating population size in maintaining genetic variation. Am Nat 160: 195-204.

Roff DA, Mousseau TA (1987). Quantitative genetics and fitness: lessons from Drosophila. Heredity 58: 103-118.

Strauss SY (1997). Floral characters link herbivores, pollinators, and plant fitness. Ecology 78: 1640-1645.

Van Noordwijk AJ, de Jong G (1986). Acquisition and allocation of resources: their influence on variation in life-history tactics. Am Nat 128: 137-142.

Whitlock MC, Fowler K (1997). The instability of studies of instability. J Evol Biol 10: 63-67.

Worley AC, Barrett SCH (2000). Evolution of floral display in Eichornia paniculata (Pontederiaceae): direct and correlated responses to selection on flower size and number. Evolution 54: 1533-1545.

\section{Appendix A}

A summary of plant species used for this review. Studies are listed alphabetically within species. Biological features considered in the analysis are noted for each 
species: Life history (A) annual, (P) perennial; Compatibility: (SC) self-compatible, (SI) self-incompatible; Floral morphology: (A) actinomorphic, (Z) zygomorphic, or (U) undescribed. Characteristics of the studies (number of populations, whether $h^{2}$ or $r_{\mathrm{g}}$ were reported) are also noted in Table A1.

Table A1

\begin{tabular}{|c|c|c|c|c|c|c|c|}
\hline Species & $\begin{array}{l}\text { Life } \\
\text { history }\end{array}$ & $\begin{array}{l}\text { Floral } \\
\text { morphology }\end{array}$ & $\begin{array}{l}\text { Mating } \\
\text { system }\end{array}$ & $\begin{array}{l}\text { No. } \\
\text { pops }\end{array}$ & $\mathrm{h}^{2}$ & $\mathrm{r}_{g}$ & Reference \\
\hline \multicolumn{8}{|l|}{ Hermaphroditic Species } \\
\hline Arabidopsis thaliana & A & A & SC & 4 & Yes & Yes & Juenger et al (2005), Ungerer et al (2002) \\
\hline Begonia semiovata & A & Z & SC & 1 & No & Yes & Agren and Schemske (1995) \\
\hline Brassica campestris & A & A & SI & 1 & No & Yes & Dorn and Mitchell-Olds (1991) \\
\hline Brassica napus & A & A & SC & 1 & No & Yes & Damgaard and Loeschcke (1994) \\
\hline Brassica rapa & A & A & SI & 2 & Yes & No & Sarkissian and Harder (2001) \\
\hline Campanula rapunculoides & $\mathrm{P}$ & A & $\mathrm{SC} / \mathrm{SI}$ & 2 & Yes & Yes & $\begin{array}{l}\text { Good-Avila and Stephenson (2002), } \\
\text { Vogler et al (1999) }\end{array}$ \\
\hline Clarkia unguiculata & A & A & SC & 1 & No & Yes & Mazer and Dawson (2001) \\
\hline Collinsia heterophylla & A & Z & SC & 4 & Yes & No & Charlesworth and Mayer (1995) \\
\hline Dalechampia scandens & $\mathrm{P}$ & Z & SC & 2 & Yes & No & Hansen et al (2003), Pelabon et al (2004) \\
\hline Danthonia spicata & $\mathrm{P}$ & Z & SC & 2 & Yes & No & Clay (1982) \\
\hline Dimorphotheca pluvialis & A & Z & SC & 1 & Yes & No & Hof et al (1999) \\
\hline Eichornia paniculata & A & $\mathrm{U}$ & SC & 3 & Yes & Yes & Worley and Barrett $(2000,2001)$ \\
\hline Gilia achilleifolia & A & A & SC & 2 & Yes & Yes & Schoen (1982) \\
\hline Gladiolus grandiflorus & $\mathrm{P}$ & $\mathrm{Z}$ & $\mathrm{U}$ & 1 & No & Yes & Rameau and Gouyon (1991) \\
\hline Heterosperma pinnatum & A & Z & SC & 2 & Yes & Yes & Venable and Burquez $(1989,1990)$ \\
\hline Impatiens pallida & A & Z & SC & 3 & Yes & Yes & $\begin{array}{l}\text { Bennington and McGraw (1996), } \\
\text { Schoen et al (1994) }\end{array}$ \\
\hline Ipomopsis aggregata & $\mathrm{P}$ & A & SI & 4 & Yes & Yes & $\begin{array}{l}\text { Campbell (1996, 1997a, b), } \\
\text { Campbell et al (1994) }\end{array}$ \\
\hline Lythrum salicara & $\mathrm{P}$ & A & SI & 3 & Yes & Yes & O'Neil (1997), O'Neil and Schmitt (1993) \\
\hline Mimulus guttatus & $\mathrm{P}$ & Z & SC & 10 & Yes & Yes & $\begin{array}{l}\text { Carr and Fenster (1994), } \\
\text { Fenster and Carr (1997), } \\
\text { Mossop et al (1994), Ritland and Ritland (1996), } \\
\text { Robertson et al (1994), van Kleunen } \\
\text { and Ritland (2004) }\end{array}$ \\
\hline $\begin{array}{l}\text { Mimulus guttatus } \\
x \text { cupriphilus }\end{array}$ & $\mathrm{P}$ & Z & SC & 1 & No & Yes & Macnair and Cumbes (1989) \\
\hline Mimulus guttatus $x$ nasutus & $\mathrm{P}$ & $\mathrm{Z}$ & SC & 1 & Yes & Yes & Fishman et al (2002) \\
\hline Mimulus micranthus & A & Z & SC & 2 & Yes & Yes & Carr and Fenster (1994) \\
\hline Nigella degenii & A & A & SC & 3 & Yes & Yes & Andersson (1997) \\
\hline Penstemon centranthifolius & $\mathrm{P}$ & A & SC & 2 & Yes & Yes & $\begin{array}{l}\text { Mitchell and Shaw (1993), } \\
\text { Mitchell et al (1998) }\end{array}$ \\
\hline Phlox drummondii & A & A & SI & 1 & Yes & Yes & Lendavi and Levin (2003) \\
\hline Plantago lanceolata & $\mathrm{P}$ & Z & SI & 2 & Yes & No & $\begin{array}{l}\text { Primack and Antonovics (1981), } \\
\text { Tonsor and Goodnight (1997) }\end{array}$ \\
\hline Polemonium viscosum & $\mathrm{P}$ & A & SI & 2 & Yes & Yes & Galen (1996), Galen and Cuba (2001) \\
\hline Primula scotica & $\mathrm{P}$ & A & $\mathrm{SC}$ & 1 & No & Yes & Mazer and Hultgard (1993) \\
\hline Primula sieboldii & $\mathrm{P}$ & A & SC & 1 & No & Yes & Nishihiro et al (2000) \\
\hline Primula stricta & $\mathrm{P}$ & A & SC & 1 & No & Yes & Mazer and Hultgard (1993) \\
\hline Puccinellia maritma & $\mathrm{P}$ & $\mathrm{U}$ & $\mathrm{U}$ & 1 & Yes & Yes & Gray and Scott (1980) \\
\hline Ranunculus reptans & $\mathrm{P}$ & A & SC & 2 & No & Yes & Prati and Schmid (2000) \\
\hline Raphanus raphanistrum & A & A & SI & 6 & Yes & Yes & $\begin{array}{l}\text { Conner (1997), Conner and Via (1993), } \\
\text { Conner et al (2003), Mazer (1987a, b) }\end{array}$ \\
\hline Raphanus sativus & A & A & SI & 8 & Yes & Yes & $\begin{array}{l}\text { Mazer and Schick (1991a, b), } \\
\text { Stanton and Young (1994), Young et al (1994) }\end{array}$ \\
\hline Scabiosa canescens & $\mathrm{P}$ & A & SC & 6 & Yes & No & Waldmann and Andersson (1998) \\
\hline Scabiosa columbaria & $\mathrm{P}$ & A & SC & 6 & Yes & No & Waldmann and Andersson (1998) \\
\hline Scleranthus annuus & A & A & SC & 1 & Yes & Yes & Svensson and Persson (1994) \\
\hline Solanum carolinense & $\mathrm{P}$ & A & SI & 3 & Yes & Yes & Elle (1998) \\
\hline Spergularia marina & A & A & SC & 7 & Yes & Yes & $\begin{array}{l}\text { Delesalle and Mazer (1995), } \\
\text { Mazer et al (1999), Mazer et al (2003) }\end{array}$ \\
\hline Talinum mengesii & $\mathrm{P}$ & A & SC & 1 & Yes & No & Carter and Murdy (1986) \\
\hline Turnera ulmifolia & $\mathrm{P}$ & A & SC & 1 & Yes & Yes & Shore and Barrett (1990) \\
\hline Dimorphic Species & & & & & & & \\
\hline Ecballium elaterium & $\mathrm{P}$ & A & SC & 1 & Yes & Yes & Costich and Meagher (2001) \\
\hline Fragaria virginiana & $\mathrm{P}$ & A & SC & 4 & Yes & Yes & Ashman $(1999,2003)$ \\
\hline Lobelia siphilitica & $\mathrm{P}$ & Z & SC & 2 & No & Yes & Caruso et al (2003) \\
\hline Phacelia linearis & A & A & SC & 3 & Yes & Yes & Eckhart (1993) \\
\hline Silene latifolia & $\mathrm{P}$ & A & SI & 1 & Yes & Yes & Delph et al (2004) \\
\hline Thalictrum dioicum & $\mathrm{P}$ & A & SI & 1 & No & Yes & Davis (2001) \\
\hline Thalictrum pubescens & $\mathrm{P}$ & A & $\mathrm{SC}$ & 1 & No & Yes & Davis (2001) \\
\hline
\end{tabular}




\section{Appendix References}

Agren J, Schemske DW (1995). Sex allocation in the monoecious herb Begonia semiovata. Evolution 49: 121-130.

Andersson S (1997). Genetic constraints on phenotypic evolution in Nigella (Ranunculaceae). Biol J Linn Society 62: $519-532$.

Ashman T-L (1999). Quantitative genetics of floral traits in a gynodioecious wild strawberry Fragaria virginiana: implications for independent evolution of female and hermaphrodite floral phenotypes. Heredity 83: 733-741.

Ashman T-L (2003). Constraints on the evolution of males and sexual dimorphism: field estimates of genetic architecture of reproductive traits in three populations of gynodioecious Fragaria virginiana. Evolution 57: 2012-2025.

Bennington CC, McGraw JB (1996). Environment-dependence of quantitative genetic parameters in Impatiens pallida. Evolution 50: 1083-1097.

Campbell DR (1996). Evolution of floral traits in a hermaphroditic plant: field measurements of heritabilities and genetic correlations. Evolution 50: 1442-1453.

Campbell DR (1997a). Genetic and environmental variation in life-history traits of a monocarpic perennial: a decade-long field experiment. Evolution 51: 373-382.

Campbell DR (1997b). Genetic correlation between biomass allocation to male and female functions in a natural population of Ipomopsis aggregata. Heredity 79: 606-614.

Campbell DR, Waser NM, Price MV (1994). Indirect selection of stigma position in Ipomopsis aggregata via a genetically correlated trait. Evolution 48: 55-68.

Carr DE, Fenster CB (1994). Levels of genetic variation and covariation for Mimulus (Scrophulariaceae) floral traits. Heredity 72: 606-618.

Carter MEB, Murdy WH (1986). Divergence for sexual and asexual reproductive characters in Talinum mengesii (Portulacaceae). Bull Torrey Bot Club 113: 259-267.

Caruso CM, Maherali H, Jackson RB (2003). Gender-specific floral and physiological traits: implications for the maintenance of females in gynodioecious Lobelia siphilitica. Oecologia 135: 524-531.

Charlesworth D, Mayer S (1995). Genetic variability of plant characters in the partial inbreeder Collinsia heterophylla (Scrophulariaceae). Am J Bot 82: 112-120.

Clay K (1982). Environmental and genetic determinants of cleistogamy in a natural population of the grass Danthonia spicata. Evolution 36: 734-741.

Conner JK (1997). Floral evolution in wild radish: the roles of pollinators, natural selection, and genetic correlations among traits. Int J Plant Sci 158: S108-S120.

Conner JK, Via S (1993). Patterns of phenotypic and genetic correlations among morphological and life-history traits in wild radish, Raphanus raphanistrum. Evolution 47: 704-711.

Conner JK, Franks R, Stewart C (2003). Expression of additive genetic variances and covariances for wild radish floral traits: comparison between field and greenhouse environments. Evolution 57: 487-495.

Costich DE, Meagher TR (2001). Impacts of floral gender and whole-plant gender on floral evolution in Ecballium elaterium (Cucurbitaceae). Biol J Linn Soc 74: 475-487.

Damgaard C, Loeschcke V (1994). Genotypic variation for reproductive characters, and the influence of pollen-ovule ratio on selfing rate in rape seed (Brassica napus). J Evo Biol 7: 599-607.

Davis SL (2001). Phenotypic and genetic correlations among floral traits in two species of Thalictrum. J Hered 92: 361-366.

Delesalle VA, Mazer SJ (1995). The structure of phenotypic variation in gender and floral traits within and among populations of Spergularia marina (Caryophyllaceae). Am J Bot 82: 798-810.

Delph LF, Frey FM, Steven JC, Gehring JL (2004). Investigating the independent evolution of the size of floral organs via
G-matrix estimation and artificial selection. Evol Devel 6: 438-448.

Dorn LA, Mitchell-Olds T (1991). Genetics of Brassica campestris. I. Genetic constraints on evolution of life-history characters. Evolution 45: 371-379.

Eckhart VM (1993). Do hermaphrodites of gynodioecious Phacelia linearis (Hydrophyllaceae) trade off seed production to attract pollinators? Biol J Linn Soc 50: 47-63.

Elle E (1998). The quantitative genetics of sex allocation in the andromonoecious perennial, Solanum carolinense (L.). Heredity 80: $481-488$.

Fenster CB, Carr DE (1997). Genetics of sex allocation in Mimulus (Scrophulariaceae). J Evol Biol 10: 641-661.

Fishman L, Kelly AJ, Willis JH (2002). Minor quantitative trait loci underlie floral traits associated with mating system divergence in Mimulus. Evolution 56: 2138-2155.

Galen C (1996). Rates of floral evolution: adaptation to bumblebee pollination in an alpine wildflower, Polemonium viscosum. Evolution 50: 120-125.

Galen C, Cuba J (2001). Down the tube: pollinators, predators, and the evolution of flower shape in the alpine skypilot, Polemonium viscosum. Evolution 55: 1963-1971.

Good-Avila SV, Stephenson AG (2002). The inheritance of modifiers conferring self-fertility in the partially self-incompatible perennial, Campanula rapunculoides L. Campanulaceae). Evolution 56: 263-272.

Gray AJ, Scott R (1980). A genecological study of Puccinellia maritime (Parl.). I. Variation estimated from single-plant samples from British populations. New Phytol 85: 89-107.

Hansen TF, Pelabon C, Armbruster WS, Carlson ML (2003). Evolvability and genetic constraint in Dalechampia blossoms: components of variance and measures of evolvabilitiy. J Evol Biol 16: 754-766.

Hof L, Keizer LCP, Elberse IAM, Dolstra O (1999). A model describing the flowering of single plants, and the heritability of flowering traits of Dimorphotheca pluvialis. Euphytica 110: $35-44$.

Juenger T, Perez-Perez JM, Bernal S, Micol JL (2005). Quantitative trait loci mapping of floral and leaf morphology traits in Arabidopsis thaliana: evidence for modular genetic architecture. Evol Devel 7: 259-271.

Lendavi G, Levin DA (2003). Rapid response to artificical selection on flower size in Phlox. Heredity 90: 336-342.

Macnair MR Cumbes QJ (1989). The genetic architecture of interspecific variation in Mimulus. Genetics 122: 211-222.

Mazer SJ (1987a). Parental effects on seed development and seed yield in Raphanus raphanistrum: implications for natural and sexual selection. Evolution 41: 355-371.

Mazer SJ (1987b). The quantitative genetics of life history and fitness components in Raphanus raphanistrum L. (Brassicaceae): ecological and evolutionary consequences of seedweight variation. Am Nat 130: 891-914.

Mazer SJ, Dawson KA (2001). Size-dependent sex allocation within flowers of the annual herb Clarkia unguiculata (Onagraceae): ontogenetic and among-plant variation. Am J Bot 88: 819-831.

Mazer SJ, Hultgard U-M (1993). Variation and covariation among floral traits within and among four species of northern European Primula (Primulaceae). Am J Bot 80: 474-485.

Mazer SJ, Schick CT (1991a). Constancy of population parameters for life-history and floral traits in Raphanus sativus L. I. Norms of reaction and the nature of genotype by environment interactions. Heredity 67: 143-156.

Mazer SJ, Schick CT (1991b). Constancy of population parameters for life-history and floral traits in Raphanus sativus L. II. Effects of planting density on phenotype and heritability estimates. Evolution 45: 1888-1907.

Mazer SJ, Delesalle VA, Neal PR (1999). Responses of floral traits to selection on primary sexual investment in Spergularia marina: the battle between the sexes. Evolution 53: 717-731. 
Mazer SJ, Lowry DE, Hansen T (2003). Effects of nutrient availability on primary sexual traits and their response to selection in Spergularia marina (Caryophyllaceae). J Evol Biol 16: $767-778$.

Mitchell RJ, Shaw RG (1993). Heritability of floral traits for the perennial wild flower Penstemon centranthifolius (Scrophulariaceae): clones and crosses. Heredity 71: 185-192.

Mitchell RJ, Shaw RG, Waser NM (1998). Pollinator selection, quantitative genetics, and predicted evolutionary responses of floral traits in Penstemon centranthifolius (Scrophulariaceae). Intl J Plant Sci 159: 331-337.

Mossop R, Macnair MR, Robertson AW (1994). Within-population variation in sexual resource allocation in Mimulus guttatus. Funct Ecol 8: 410-418.

Nishihiro J, Washitani I, Thomson JD, Thomson BA (2000) Patterns and consequences of stigma height variation in a natural population of a distylous plant, Primula sieboldii. Funct Ecol 14: 502-512.

O'Neil P (1997). Natural selection on genetically correlated phonological characters in Lythrum salicaria L. (Lythraceae). Evolution 51: 267-274.

O'Neil P, Schmitt J (1993). Genetic constraints on the independent evolution of male and female reproductive traits in the tristylous plant Lythrum salicaria. Evolution 47: 1457-1471.

Pelabon C, Hansen TF, Carlson ML, Armbruster WS (2004). Variational and genetic properties of developmental stability in Dalechampia scandens. Evolution 58: 504-514.

Prati D, Schmid B (2000). Genetic differentiation of life-history traits within populations of the clonal plant Ranunculus reptans. Oikos 90: 442-456.

Primack RB, Antonovics J (1981). Experimental ecological genetics in Plantago. V. Components of seed yield in the ribwort plantain Plantago lanceolata L. Evolution 35: 10691079.

Rameau C, Gouyon P-H (1991). Resource allocation to growth, reproduction, and survival in Gladiolus: the cost of male function. J Evol Biol 4: 291-307.

Ritland K, Ritland C (1996). Inferences about quantitative inheritance based on natural population structure in the yellow monkeyflower, Mimulus guttatus. Evolution 50: 1074-1082.

Robertson AW, Diaz A, Macnair MR (1994). The quantitative genetics of floral characteristics in Mimulus guttatus. Heredity 72: 300-311.

Sarkissian TS, Harder LD (2001). Direct and indirect responses to selection on pollen size in Brassica rapa L. J Evol Biol 14 456-468.

Schoen DJ (1982). The breeding system of Gilia achilleifolia: variation in floral characteristics and outcrossing rate Evolution 36: 352-360.
Schoen DJ, Bell G, Lechowicz MJ (1994). The ecology and genetics of fitness in forest plants. IV. Quantitative genetics of fitness components in Impatiens pallida (Balsaminaceae). Am J Bot 81: 232-239.

Shore JS, Barrett SCH (1990). Quantitative genetics of floral characters in homostylous Turnera ulmifolia var. angustifolia Willd. (Turneraceae). Heredity 64: 105-112.

Stanton ML, Young HJ (1994). Selecting for floral character associations in wild radish, Raphanus sativus L. J Evol Biol 7: 271-285.

Svensson L, Persson H (1994). Quantitative genetics of stamen number in the selfing Scleranthus anuus (Caryophyllaceae). Am J Bot 81: 1112-1118.

Tonsor SJ, Goodnight CJ (1997). Evolutionary predictability in natural populations: do mating system and nonadditive genetic variance interact to affect heritabilities in Plantago lanceolata? Evolution 51: 1773-1784.

Ungerer MC, Halldorsdottir SS, Modliszewski JL, Mackay TFC, Purugganan MD (2002). Quantitative trait loci for inflorescence development in Arabidopsis thaliana. Genetics 160: 1133-1151.

Van Kleunen M, Ritland K (2004). Predicting evolution of floral traits associated with mating system in a natural plant population. J Evol Biol 17: 1389-1399.

Venable DL, Burquez AM (1989). Quantitative genetics of size, shape, life-history, and fruit characteristics of the seedheteromorphic composite Heterosperma pinnatum. I. Variation within and among populations. Evolution 43: 113-124.

Venable DL, Burquez AM (1990). Quantitative genetics of size, shape, life-history, and fruit characteristics of the seedheteromorphic composite Heterosperma pinnatum. II. Correlation structure. Evolution 44: 1748-1763.

Vogler DW, Peretz S, Stephenson AG (1999). Floral plasticity in an iteroparous plant: the interactive effects of genotype, environment, and ontogeny in Campanula rapunculoides (Campanulaceae). Am J Bot 86: 482-494.

Waldmann P, Andersson S (1998). Comparison of quantitative genetic variation and allozyme diversity within and between populations of Scabiosa canescens and S. columbaria. Heredity 81: 79-86.

Worley AC, Barrett SCH (2000). Evolution of floral display in Eichhornia paniculata (Pontederiaceae): direct and correlated responses to selection on flower size and flower number. Evolution 54: 1533-1545.

Worley AC, Barrett SCH (2001). Evolution of floral display in Eichhornia paniculata (Pontederiaceae): genetic correlations between flower size and number. J Evol Biol 14: 469-481.

Young HJ, Stanton ML, Ellstrand NC, Clegg JM (1994). Temporal and spatial variation in heritability and genetic correlations among floral traits in Raphanus sativus, wild radish. Heredity 73: 298-308. 